\title{
BMJ Open A small-area analysis of inequalities in chronic disease prevalence across urban and non-urban communities in the Province of Nova Scotia, Canada, 2007-2011
}

\author{
Mikiko Terashima, ${ }^{1,2}$ Daniel G C Rainham, ${ }^{1}$ Adrian R Levy ${ }^{2}$
}

To cite: Terashima M, Rainham DGC, Levy AR. A small-area analysis of inequalities in chronic disease prevalence across urban and non-urban communities in the Province of Nova Scotia, Canada, 2007-2011. BMJ Open 2014;4:e004459. doi:10.1136/bmjopen-2013004459

- Prepublication history for this paper is available online. To view these files please visit the journal online (http://dx.doi.org/10.1136/ bmjopen-2013-004459).

Received 11 November 2013 Revised 15 April 2014 Accepted 23 April 2014

CrossMark

\footnotetext{
${ }^{1}$ Environmental Science Program, Dalhousie University, Halifax, Canada ${ }^{2}$ Department of Community Health \& Epidemiology, Dalhousie University, Halifax, Canada
}

Correspondence to Dr Mikiko Terashima; mikiko.terashima@dal.ca

\section{ABSTRACT \\ Background: Small-area studies of health inequalities often have an urban focus, and may be limited in their translatability to non-urban settings. Using small-area units representing communities, this study assessed the influence of living in different settlement types (urban, town and rural) on the prevalence of four chronic diseases (heart disease, cancer, diabetes and stroke) and compared the degrees of associations with individual-level and community-level factors among the settlement types.}

Methods: The associations between community-level and individual-level characteristics and prevalence of the chronic diseases were assessed using logistic regression (multilevel and non-multilevel) models. Individual-level data were extracted from the Canadian Community Health Survey (2007-2011). Indices of material deprivation and social isolation and the settlement type classification were created using the Canadian Census.

Results: Respondents living in towns were $21 \%$ more likely to report one of the diseases than respondents living in urban communities even after accounting for individual-level and community-level characteristics. Having dependent children appeared to have protective effects in towns, especially for males (OR: 0.49 (95\% $\mathrm{Cl} 0.27$ to 0.90$)$ ). Unemployment had a strong association for all types of communities, but being unemployed appeared to be particularly damaging to health of males in urban communities (OR: 2.48 (95\% Cl 1.43 to 4.30)).

Conclusions: The study showed that those living in non-urban settings, particularly towns, experience extra challenges in maintaining health above and beyond the socioeconomic condition and social isolation of the communities, and individual demographic, behavioural and socioeconomic attributes. Our findings also suggest that health inequality studies based on urbanonly settings may underestimate the risks by some factors. Ways to devise meaningful small-area units comparable in all settlement types are necessary to help plan effective provision of chronic disease-related health services and programmes on a regional scale.

\section{Strengths and limitations of this study}

Existing studies of health inequalities are usually confined either a small-area level but urban areas only, or across urban and non-urban areas but using a larger area unit. This study addresses the weaknesses of both types of studies.

- The study found some nuanced differences among the various settlement types, where residents in towns experience extra challenges in maintaining health above and beyond the socioeconomic condition and social isolation of the communities, and individual demographic, behavioural and socioeconomic attributes.

- The strong negative influence of unemployment and the relatively benign influence of low household income in town and rural communities compared with urban communities suggest possible differences in the importance of the psychosocial and (neo)material explanations of socioeconomic position in different settlement types.

- Cross-sectional data were used, limiting our ability to determine clear cause-effect relationships between health and individual and arealevel risk factors investigated.

\section{INTRODUCTION}

Interest in the influence of living environment in the production of health inequalities has grown rapidly in public health and epidemiology in the past two decades. In particular, the neighbourhood social and socioeconomic conditions such as material deprivation, ${ }^{1}{ }^{2}$ residential instability ${ }^{2}$ and lack of social support ${ }^{3}$ have been found to be contributory factors to higher occurrences of cardiovascular disease, cancer and diabetes, ${ }^{45}$ mental health disorders, ${ }^{6}{ }^{7}$ lower self-rated health and life expectancy, ${ }^{1}{ }^{6}$ even after accounting for individual-level common risk factors such as income, education and smoking status. 
What is relatively understudied, however, is the small-area level evidence for the effects of living environment on various health conditions in a regional context, inclusive of urban and non-urban settings. The majority of 'neighbourhood' or small-area evidence of health inequalities has been based on urban areas. ${ }^{8-10}$ When rural and urban areas were included in a study, analyses have often been based on larger-area units, since small-area investigation in rural areas pose practical data problems due to the small population size. ${ }^{11}$ The results of studies about rural-urban differences in health and disease conditions have been varied, partially due to the varying sizes of area units employed. ${ }^{10}$

There are two main reasons for studying small-area level health inequalities across urban and non-urban settings. First, the relationships between living environment and health, or even relationships between individuallevel factors and health, may not be the same when compared between urban and non-urban settings. ${ }^{12}$ Second, not only local scale- (eg, health districts), but also larger, regional scale- (eg, a province) decision-making on intervention programs and policies often requires identification of most at-risk neighbourhoods or communities within the jurisdiction. For example, a provincial programme may need to identify priority communities to dispatch provincially funded specialist teams based on distributions of present health statuses and associated risk factors.

This study focuses on improving knowledge about small-area health inequalities by assessing the prevalence of chronic diseases (heart disease, cancer, diabetes and stroke) and their relationships with settlement (urban, town and rural) types. The specific objectives are:

1. To assess the influence on health of living in non-urban communities compared with living in urban communities after taking into account common individual risk factors and community-level characteristics.

2. To compare the extents of the effects by observed individual-level and community-level characteristics among urban and non-urban settlement types.

Nova Scotia has a relatively small population and few studies $^{13}$ have been conducted to examine withinprovince inequalities in health using small-area equivalents to neighbourhood or community as a unit of investigation. Nova Scotia has some of the highest incidence and mortality rates from chronic diseases in the country. ${ }^{14}$ The extents of the influence of area-level factors on health outcomes in the province-particularly after accounting for individual risk factors-remain largely unknown.

\section{METHODS}

\section{Small-area units and data}

Nova Scotia has a set of administrative area units called 'communities' ( $\mathrm{n}=276)$, developed by the Nova Scotia government to better represent generally perceived community identities for the purpose of public policy development and decision-making. ${ }^{15}$ Our study employed the communities as a basis of analysis. 'Communities' are considered in this study as collections or clusters of neighbourhoods ${ }^{16}$ with shared identity and social processes relevant to their health. ${ }^{17}$ Administrative area units commonly used in Canada to represent 'neighbourhoods' such as census tracts and census dissemination areas (DAs) ${ }^{8918}$ are either unavailable or not well suited to represent perceived neighbourhoods in rural areas. ${ }^{19}$ Census subdivisions, which are sometimes coined as communities, ${ }^{20}$ still contain diverse subareas, most likely masking potentially important within-area variations. With the absence of rural area units considered as good proximation of perceived neighbourhood entities comparable with urban neighbourhoods, these community units are the most suitable, smallest area units available.

The average community population size was 3456 (median 1797), ranging from 110 to 31000 in 2006. In order for each area to have a sufficient sample size (10 or more) of individual-level data, some adjacent communities were combined, resulting in 200 areas-still fitting with our working definition of 'communities'. We used the Canadian Census data (2006) to derive three characteristics for these 200 communities: (1) material deprivation, (2) social isolation and (3) settlement type (urban, town or rural). Scores of material deprivation were based on a composite of three variables (average individual income, proportion of people without high school diploma (population ages 20+) and unemployment rate (population ages 25+)). Social isolation was comprised of the proportion of lone parents, of people who are separated, widowed or divorced, and of people living alone (population ages $15+$ ). ${ }^{21}$

Communities were classified into three settlement types based on population density (per kilometre road) using geometric intervals - a method which minimises within-group variance-and using Google Earth satellite images. $^{22}$ There were 29 'urban' (Halifax Metro and adjacent) communities, 58 'towns' (mid-size to small-size towns outside of Halifax Metro) and 113 sparse 'rural' communities. Figure 1 shows the spatial distribution of communities in the province by three settlement types.

\section{Individual-level data}

The Canadian Community Health Survey (CCHS) was accessed under a contractual agreement with Statistics Canada, and the project and data usage protocol were followed according to their regulations. CCHS, a national cross-sectional survey, contains data on various health outcomes, sociodemographic characteristics and health-related behaviours of the respondents 12 years and older. Combining the five most recent available years (2007-2011) resulted in a dataset containing 12259 respondents for Nova Scotia. Postal code and Census DA information of the respondents were used to assign communities. Many of the DA boundaries fell into one community, in which case the community assignment was 


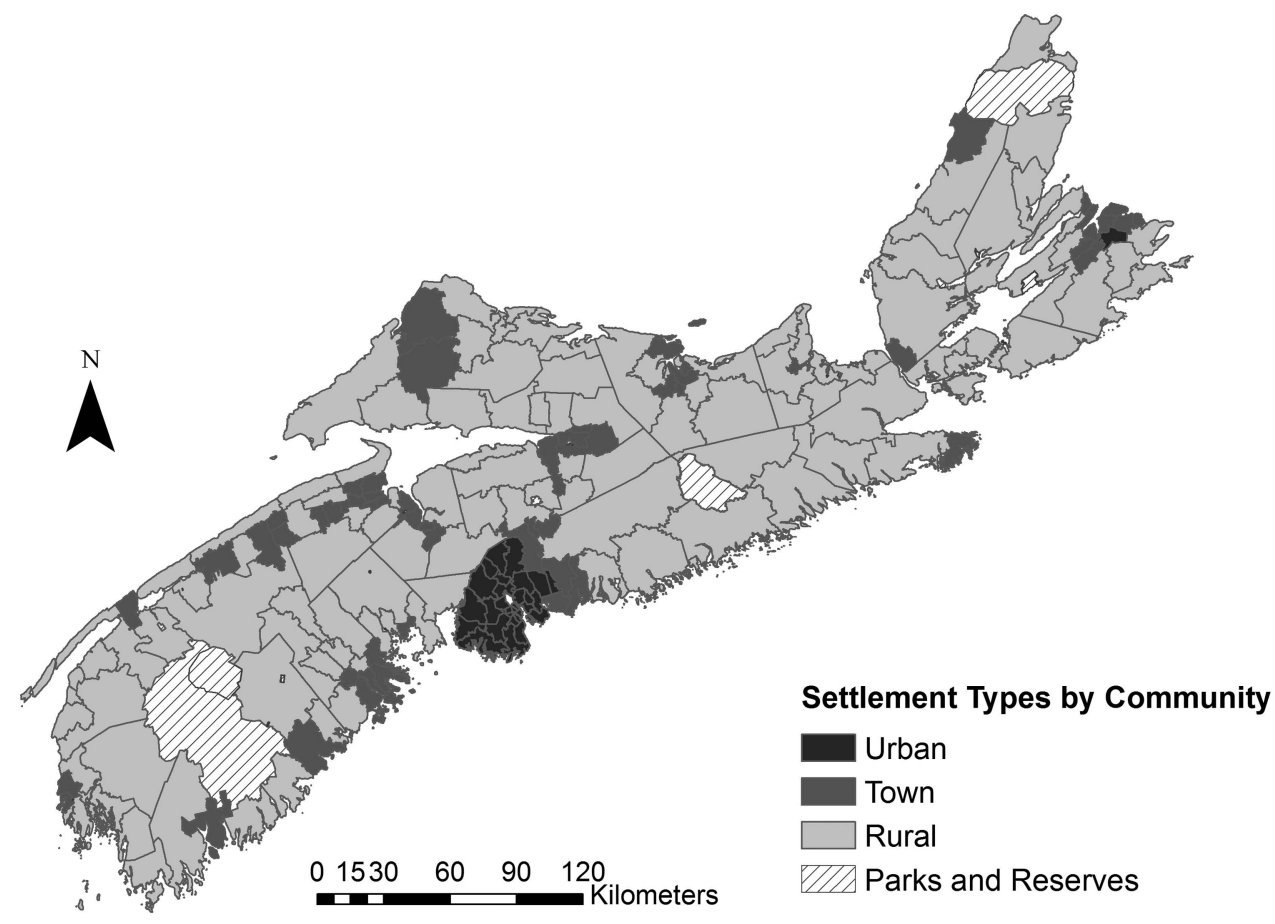

Figure 1 Settlement types (urban, town and rural) by community, Nova Scotia, Canada.

straightforward. Where DA boundaries intersected more than one community, the concentration of residences with the same postal code was examined. Usually, residences with the same postal codes are clustered in one community, with only a few residences crossing over into another community. We therefore chose the community containing a majority of the residences with the same postal code. There were 1026 records for which the community could not be determined. Removing these records resulted in 11233 records. The self-reported presence of diagnosed chronic diseases was used as a dependent variable. Dichotomous responses regarding heart disease, diabetes and stroke in the Survey (eg, Do you have diabetes? -1 for yes and 0 otherwise) were used as they were. For cancer, the responses regarding the current and past diagnosis (also dichotomous) were combined. The responses for the four diseases were also combined to assess the associations between the explanatory variables and having at least one of the disease outcomes. Ages of the respondents were classified into: 24 years or younger; 25-44; 45-64; and 65+ years of age. Marital status was classified into: couple-married or in a common-law relationship; and single-single or never married, separated, divorced or widowed. The status of having dependants was dichotomised into those with 17-year-old or younger children and those without. A body mass index of 25 and higher was grouped into 'overweight or obese' versus 'not overweight or obese'. Three activity levels-active, moderately active, and inactivewere based on the calculation of total daily energy expenditure from the duration and frequency of the respondents' leisure time and transportation activities. ${ }^{23}$ Smoking status was determined by whether the respondents smoked daily or occasionally in the last 12 months. Education level was classified into those with: postsecondary education; some postsecondary education; completed high school; and some high school education. Household income was categorised into: less than $\$ 20000 ; \quad \$ 20000-\$ 39999 ; \quad \$ 40000-\$ 59999 ; \quad \$ 60000$ $\$ 79$ 999; and $\$ 80000$ plus. Since non-income assets may better indicate economic standing in non-urban households than income, we also included home ownership. The test of multicollinearity showed no significant inflation or high correlations between the two variables. There was no significant difference between retained and removed respondents for whom communities were not identifiable.

\section{Analyses}

Multilevel logistic regression models were employed as an initial model to examine the odds of reporting each and at least one of the four diseases. The glimmix procedure in SAS (Cary, North Carolina, USA) estimates random effects using pseudolikelihood. Multilevel models account for the clustering of individual characteristics within areas and allow the examination of residual components for different levels (eg, individual levels and area levels) separately. ${ }^{24}$ Random intercepts at an area level allow the calculation of intraclass correlation (ICC), and the ICC of an empty model (Model 0) indicates the estimate of the total variance in the outcome attributed to differences between areas.

To assess the influence of living in non-urban settlement types, the odds of diseases were assessed with settlement type as a sole explanatory variable (Model 1), then with the other community characteristics (Model 2), 
Table 1 Descriptive statistics of respondents stratified by settlement type, Nova Scotia 2007-2011 ( $n=11233)$

\begin{tabular}{|c|c|c|c|}
\hline Variable & Urban (\%) & Town (\%) & Rural (\%) \\
\hline Total respondents included & $2776(41.0)$ & 5349 (37.5) & $3108(21.4)$ \\
\hline \multicolumn{4}{|c|}{ Self-reported diagnosed heart disease } \\
\hline No & 2611 (95.9) & 4821 (92.4) & $3830(93.4)$ \\
\hline Yes & $161(5.9)$ & $520(7.6)$ & $271(6.6)$ \\
\hline (Missing=19) & & & \\
\hline \multicolumn{4}{|c|}{ Self-reported diagnosed cancer (current and past) } \\
\hline No & 2786 (91.4) & $4796(91.7)$ & $2556(93.4)$ \\
\hline Yes & $220(8.6)$ & $512(8.9)$ & $321(6.6)$ \\
\hline (Missing=2) & & & \\
\hline \multicolumn{4}{|c|}{ Self-reported diagnosed diabetes } \\
\hline No & 2567 (93.9) & $4786(91.7)$ & $2795(92.0)$ \\
\hline Yes & $209(6.1)$ & $560(8.3)$ & $313(8.0)$ \\
\hline (Missing=3) & & & \\
\hline \multicolumn{4}{|c|}{ Self-reported diagnosed stroke } \\
\hline No & $2746(98.5)$ & $5248(98.6)$ & $3051(99.2)$ \\
\hline Yes & $28(1.5)$ & $96(1.4)$ & $54(0.8)$ \\
\hline (Missing=10) & & & \\
\hline \multicolumn{4}{|c|}{ Self-reported diagnosed any of the four diseases } \\
\hline No & $2282(85.7)$ & 3994 (79.2) & $2368(81.0)$ \\
\hline Yes & $494(14.3)$ & $1355(20.8)$ & $740(19.0)$ \\
\hline \multicolumn{4}{|l|}{ Age (years) } \\
\hline $12-24$ & $475(20.2)$ & $781(16.5)$ & $446(17.6)$ \\
\hline $25-44$ & $823(34.6)$ & $1238(28.1)$ & $641(25.2)$ \\
\hline $45-64$ & $903(31.6)$ & $1768(35.3)$ & 1167 (37.9) \\
\hline $65+$ & $575(13.5)$ & $1562(20.1)$ & $854(19.3)$ \\
\hline \multicolumn{4}{|l|}{ Marital status } \\
\hline Single & $1345(56.5)$ & $2603(58.1)$ & $1696(62.2)$ \\
\hline Couple & $1431(43.8)$ & $2746(41.9)$ & $1412(37.8)$ \\
\hline \multicolumn{4}{|l|}{ Home ownership } \\
\hline Own home & $1886(68.1)$ & $3980(78.6)$ & 2767 (89.9) \\
\hline Do not own home & $864(31.9)$ & $1302(21.4)$ & $314(10.1)$ \\
\hline (Missing=118) & & & \\
\hline \multicolumn{4}{|c|}{ Dependent children (17 years old or less) } \\
\hline No & $1995(63.1)$ & $4011(66.0)$ & $2333(64.8)$ \\
\hline Yes & 781 (36.9) & $1338(34.0)$ & 775 (35.2) \\
\hline \multicolumn{4}{|l|}{ Employed } \\
\hline Yes & $1741(80.2)$ & $2829(72.8)$ & $1676(71.4)$ \\
\hline No & $619(19.8)$ & $1526(27.2)$ & $916(28.6)$ \\
\hline (Missing=1926) & & & \\
\hline \multicolumn{4}{|l|}{ Overweight or obese } \\
\hline No & 1361 (53.8) & 2877 (58.9) & 1719 (58.9) \\
\hline Yes & $1270(46.2)$ & $2144(41.1)$ & $1181(41.6)$ \\
\hline (Missing=681) & & & \\
\hline \multicolumn{4}{|l|}{ Activity } \\
\hline Active & $849(34.8)$ & $1276(25.6)$ & $716(25.8)$ \\
\hline Moderately active & $638(226)$ & 1261 & $685(23.6)$ \\
\hline Inactive & $1221(42.6)$ & $2649(48.9)$ & $1584(50.6)$ \\
\hline (Missing=354) & & & \\
\hline \multicolumn{4}{|l|}{ Current smoker } \\
\hline No & $2203(78.7)$ & $4150(75.6)$ & $2471(76.6)$ \\
\hline Yes & $573(21.3)$ & $1194(24.4)$ & $633(23.4)$ \\
\hline (Missing=8) & & & \\
\hline \multicolumn{4}{|l|}{ Educational attainment } \\
\hline Postsecondary & $1631(59.7)$ & $2630(53.1)$ & $1387(46.0)$ \\
\hline Some postsecondary & $200(7.7)$ & $331(6.3)$ & $152(4.9)$ \\
\hline High school diploma & $342(13.4)$ & $736(14.6)$ & $420(14.2)$ \\
\hline $\begin{array}{l}\text { No high school } \\
\text { (Missing=163) }\end{array}$ & 569 (19.2) & $1560(26.0)$ & $1111(35.0)$ \\
\hline
\end{tabular}


Table 1 Continued

\begin{tabular}{|c|c|c|c|}
\hline Variable & Urban (\%) & Town (\%) & Rural (\%) \\
\hline \multicolumn{4}{|l|}{ Household income } \\
\hline$>\$ 80000$ & $1032(42.4)$ & $1483(34.2)$ & 748 (28.3) \\
\hline$\$ 60000-\$ 79999$ & 509 (19.3) & 809 (16.7) & $508(18.4)$ \\
\hline$\$ 40000-\$ 59999$ & $490(16.4)$ & $964(18.5)$ & $546(18.6)$ \\
\hline$\$ 20000-\$ 39000$ & $501(15.2)$ & $1236(19.4)$ & $817(23.6)$ \\
\hline$<\$ 20000$ & $245(6.7)$ & $857(11.1)$ & $489(10.7)$ \\
\hline \multicolumn{4}{|c|}{ Community-level variables } \\
\hline \multicolumn{4}{|l|}{ Material deprivation } \\
\hline Q1 & 2254 (81.1) & $911(18.4)$ & $90(2.8)$ \\
\hline Q2 & $410(14.8)$ & 1674 (31.3) & $451(13.9)$ \\
\hline Q3 & $93(3.2)$ & $1340(22.7)$ & $712(22.6)$ \\
\hline Q4 & $19(0.9)$ & 1195 (23.3) & $898(29.0)$ \\
\hline Q5 & $0(0)$ & $229(4.3)$ & $957(31.7)$ \\
\hline \multicolumn{4}{|l|}{ Social isolation } \\
\hline Q1 & $732(27.9)$ & 457 (11.3) & $541(16.3)$ \\
\hline Q2 & $502(19.2)$ & $366(7.9)$ & $743(22.4)$ \\
\hline Q3 & $176(6.9)$ & $195(3.8)$ & $865(29.6)$ \\
\hline Q4 & $0(0)$ & $862(14.2)$ & $719(24.5)$ \\
\hline Q5 & $1366(46.0)$ & 3469 (62.8) & $240(7.2)$ \\
\hline \multicolumn{4}{|l|}{ Survey year } \\
\hline 2007 & 591 (19.3) & 1126 (19.4) & $671(21.7)$ \\
\hline 2008 & 560 (19.7) & 1190 (20.5) & 604 (18.9) \\
\hline 2009 & 538 (19.8) & 984 (20.0) & $626(20.0)$ \\
\hline 2010 & $542(20.4)$ & 1002 (20.2) & 593 (19.3) \\
\hline 2011 & 595 (20.8) & 1047 (20.0) & $614(20.2)$ \\
\hline
\end{tabular}

followed by a model adjusting for only individual-level characteristics (Model 3). The full model (Model 4) adjusted for individual-level and community-level characteristics.

To compare the extent of risk by observed factors among the settlement types, the fully adjusted models were fit for the combination of four diseases to: (1) urban communities only, (2) towns only and (3) rural communities only subdata. If there were substantial differences in the extent of effects by any factors among the settlement types-especially between urban and other types-then it would warrant caution in assuming levels of risks in non-urban areas based on the findings from urban-area analyses.

Additionally, we examined whether effects of some risk factors are mediated by gender. Men typically take the main income earning responsibility in a household, and being unemployed may produce high stress for men, having stronger negative effects on their health than for women. ${ }^{25} \mathrm{~A}$ few studies found a stronger risk of heart-related conditions for women by neighbourhood deprivation and a protective effect of having dependent children on hypertension for women. ${ }^{26} 27$ These three interaction terms were tested in the models.

\section{RESULTS}

Distributions of respondents by their characteristics, and the proportion of the weighted population (to account for the survey's sampling design, non-response and poststratification) are shown in table 1 . The sample consisted of $2276(41 \%)$ urban, $5349(37.5 \%)$ town and 3108 $(21 \%)$ rural respondents. Out of 11233 respondents, 2589 (17.7\% of the population) reported having at least one of the four diseases. The comparisons in mean probability of having the diseases among urban communities, towns and rural communities are shown in figure 2 . The mean probability of having any of the diseases was statistically significantly lower $(\mathrm{p}<0.0001)$ for urban communities than for non-urban communities. There were no statistically significant differences between towns and rural communities for any of the diseases.

The multilevel logistic regression showed that living in rural communities and towns was associated with at least one of the four diseases in unadjusted models (table 2). Once other community characteristics were included, the associations remained statistically significant for heart disease and cancer, while they attenuated for diabetes and stroke. Odds risks of material deprivation and social isolation are based on the comparison between the most and the least deprived/isolated quintile groups. In the full models, living in towns remained a significant risk factor for heart disease (OR $1.47 \quad(95 \%$ CI 1.07 to 2.02$)$ ), cancer (OR 1.42 (95\% 1.02 to 1.99$)$ ) and the four diseases together (OR 1.22 (95\% 1.00 to $1.50)$ ). Material deprivation and social isolation were not significant in the full models except for material deprivation for diabetes (OR: 1.62 (95\% 1.10 to 2.38)). 


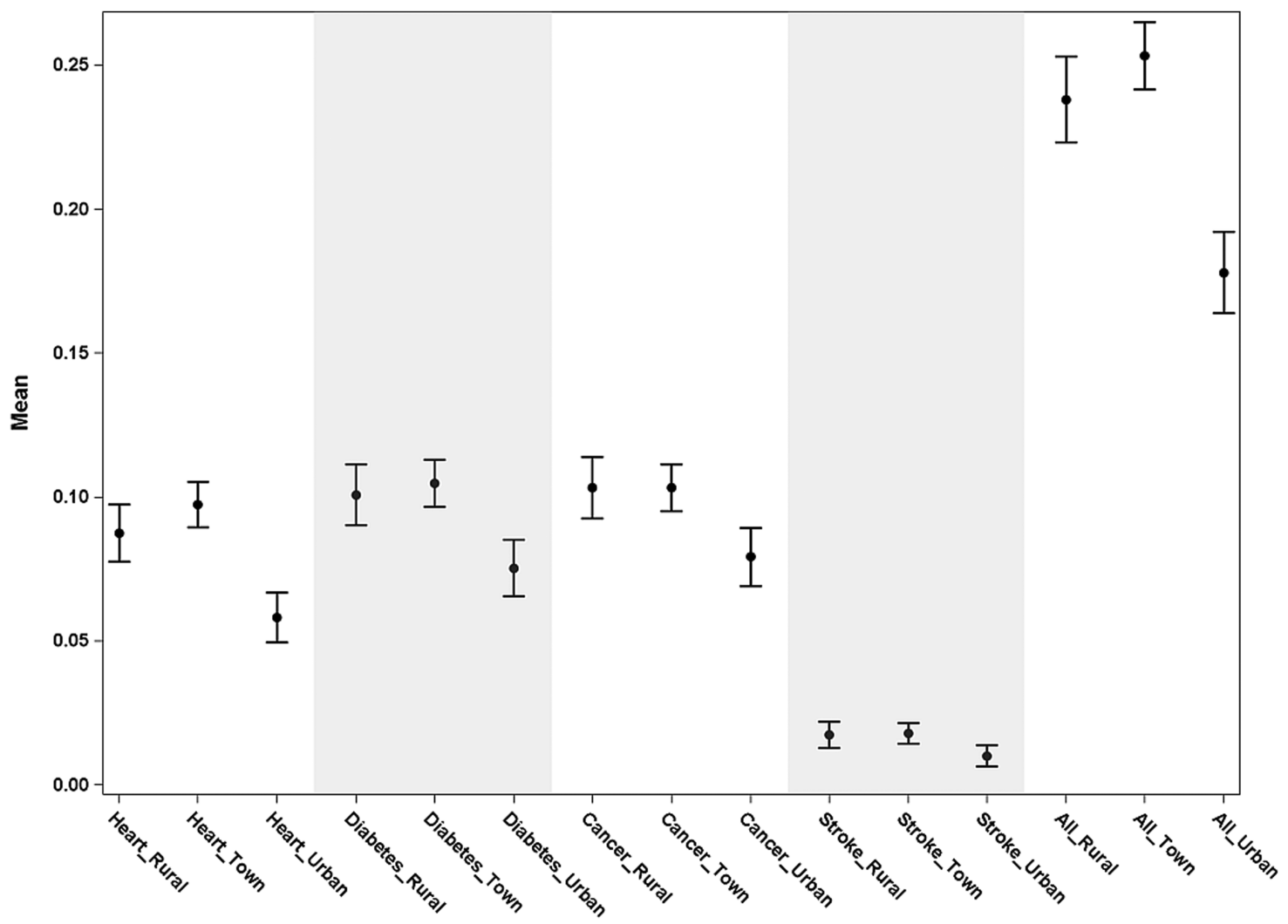

Figure 2 Comparisons in predicted mean probability (eg, $0.25=25 \%$ probability) with $95 \% \mathrm{Cl}$ of having heart disease, diabetes, cancer, stroke and any of the four diseases by settlement type.

The ICCs of empty models for individual diseases were between 0.0007 (stroke) and 0.008 (diabetes) 一 that is, $0.07-0.8 \%$ of the variance in health outcomes is attributed to between-community differences. The ICC for the combination of four diseases was $0.011-$ small but within the lower range reported in previous studies examining the area-level effects on cardiovascular diseases. ${ }^{26}{ }^{28}$ Nevertheless, the multilevel structure of the model was dropped for further analysis because: (1) none of the communities' random intercepts were statistically significantly different from the provincial average; and (2) the ORs of all explanatory factors were nearly identical between the fully adjusted models with and without the random component.

Some differences in the extent of the effects by a few factors were observed among settlement types (table 3). Having dependants was a significant protective factor for those living in towns (OR 0.58 (95\% CI 0.41 to 0.81 )), and it was additionally protective for males (OR 0.49 (95\% CI 0.27 to 0.90$)$ ). Unemployed residents in towns (OR 2.31 (95\% CI 1.88 to 2.82)) and rural communities (OR 2.27 (95\% CI 1.75 to 2.95)) were more than twice as likely to report a disease as unemployed residents in urban communities (OR 1.53 (95\% CI 1.09 to 2.14)). In urban communities, unemployed males were nearly $150 \%$ more likely to report a disease than unemployed females and employed males and females (OR 2.48 (95\% CI 1.43 to 4.30$)$ ). Moderate-activity level versus high-activity level did not present significant differences in risk for all settlement types. However, being inactive was a strong risk factor in urban communities (OR 1.90 (95\% CI 1.34 to 2.70$)$ ), and a less strong but significant factor for towns (OR 1.25 (95\% CI 1.00 to 1.56)).

The cross-level interaction between material deprivation and gender was not statistically significant and adding it did not improve the model fit; therefore, it was not included in the final models. Regardless of the settlement types, marital status (even if the 'single' category was split into 'single or never married' and 'separated, divorced and widowed'), home ownership, smoking status and education were not significant factors in the full models.

\section{DISCUSSION}

The main purpose of this study was to assess the associations between small-area level inequalities in the prevalence of chronic diseases and living in different settlement types, and compare the degrees of association with individual and community characteristics among these settlement types. The Nova Scotia governmentdesigned 'communities' served as a set of small-area units: (1) representative of perceived communities in which social processes and relationships relevant to health most likely occur; and (2) comparable between urban and non-urban settings.

The findings of the study suggest that those living in non-urban settings, particularly towns, experience extra 
Table 2 Settlement type as contextual risks on four types of chronic diseases, Nova Scotia, 2007-2011

\begin{tabular}{|c|c|c|c|c|}
\hline & $\begin{array}{l}\text { Unadjusted } \\
\text { (Model 1) } \\
\text { OR }(95 \% \mathrm{Cl})\end{array}$ & $\begin{array}{l}\text { Unadjusted with } \\
\text { deprivation and } \\
\text { social isolation (Model } 2) \\
\text { OR }(95 \% \mathrm{Cl})\end{array}$ & $\begin{array}{l}\text { Adjusted for } \\
\text { individual risk } \\
\text { factors (Model 3) } \\
\text { OR }(95 \% \mathrm{Cl})\end{array}$ & $\begin{array}{l}\text { Adjusted for individual } \\
\text { risk factors and } \\
\text { deprivation and } \\
\text { social isolation (Model } 4) \\
\text { OR }(95 \% \mathrm{Cl})\end{array}$ \\
\hline \multicolumn{5}{|l|}{ Four diseases } \\
\hline Urban & 1.00 & 1.00 & 1.00 & 1.00 \\
\hline Town & 1.55 (1.33 to 1.81$)$ & 1.35 (1.13 to 1.60$)$ & $1.23(1.04$ to 1.49$)$ & $1.22(1.00$ to 1.50$)$ \\
\hline Rural & 1.46 (1.25 to 1.71$)$ & 1.19 (0.95 to 1.48$)$ & $1.12(0.93$ to 1.33$)$ & $1.10(0.85$ to 1.43$)$ \\
\hline Material deprivation Q1 & & 1.00 & & 1.00 \\
\hline Q5 & & 1.30 (1.03 to 1.65$)$ & & $0.97(0.72$ to 1.29$)$ \\
\hline Social isolation Q1 & & 1.00 & & 1.00 \\
\hline Q5 & & 1.25 (1.04 to 1.49$)$ & & $1.11(0.89$ to 1.38$)$ \\
\hline \multicolumn{5}{|l|}{ Heart } \\
\hline Urban & 1.00 & 1.00 & 1.00 & 1.00 \\
\hline Town & 1.75 (1.46 to 2.10$)$ & $1.57(1.25$ to 1.98$)$ & 1.37 (1.06 to 1.77$)$ & 1.47 (1.07 to 2.02$)$ \\
\hline Rural & 1.55 (1.27 to 1.90$)$ & 1.40 (1.04 to 1.88$)$ & 1.25 (0.94 to 1.66$)$ & 1.41 (0.94 to 2.11$)$ \\
\hline Material deprivation Q1 & & 1.00 & 1.00 & 1.00 \\
\hline Q5 & & $1.14(0.83$ to 1.57$)$ & & $0.74(0.48$ to 1.16$)$ \\
\hline Social isolation Q1 & & 1.00 & & 1.00 \\
\hline Q5 & & 1.27 (1.00 to 1.63$)$ & & $1.11(0.79$. to 1.56$)$ \\
\hline \multicolumn{5}{|l|}{ Cancer (current and past) } \\
\hline Urban & 1.00 & 1.00 & 1.00 & 1.00 \\
\hline Town & 1.34 (1.14 to 1.58$)$ & 1.29 (1.05 to 1.59$)$ & 1.15 (0.94 to 1.42$)$ & $1.42(1.02$ to 1.99$)$ \\
\hline Rural & 1.34 (1.12 to 1.60$)$ & 1.33 (1.01 to 1.74$)$ & $1.16(0.92$ to 1.46$)$ & $1.22(0.94$ to 1.57$)$ \\
\hline Material deprivation Q1 & & 1.00 & & 1.00 \\
\hline Q5 & & $1.10(0.82$ to 1.47$)$ & & $0.76(0.52$ to 1.10$)$ \\
\hline Social isolation Q1 & & 1.00 & & 1.00 \\
\hline Q5 & & 1.35 (1.07 to 1.69$)$ & & $1.10(0.83$ to 1.46$)$ \\
\hline \multicolumn{5}{|l|}{ Diabetes } \\
\hline Urban & 1.00 & 1.00 & 1.00 & 1.00 \\
\hline Town & 1.44 (1.22 to 1.70$)$ & $1.02(0.82$ to 1.26$)$ & 1.07 (0.86 to 1.32$)$ & $0.88(0.67$ to 1.15$)$ \\
\hline Rural & 1.38 (1.15 to 1.65$)$ & 0.80 (0.61 to 1.05$)$ & $0.96(0.75$ to 1.21$)$ & 0.68 (0.48 to 0.96$)$ \\
\hline Material deprivation Q1 & & 1.00 & & 1.00 \\
\hline Q5 & & 1.99 (1.46 to 2.70$)$ & & 1.62 (1.10 to 2.38$)$ \\
\hline Social isolation Q1 & & 1.00 & & 1.00 \\
\hline Q5 & & $0.96(0.76$ to 1.20$)$ & & 0.85 (0.64 to 1.13$)$ \\
\hline \multicolumn{5}{|l|}{ Stroke } \\
\hline Urban & 1.00 & 1.00 & 1.00 & 1.00 \\
\hline Town & 1.79 (1.10 to 2.75$)$ & $1.26(0.74$ to 2.16$)$ & $1.21(0.65$ to 2.25$)$ & $1.94(0.73$ to 5.11$)$ \\
\hline Rural & 1.74 (1.18 to 2.74$)$ & $1.42(0.71$ to 2.81$)$ & 1.56 (0.80 to 3.07$)$ & $1.00(0.47$ to 2.16$)$ \\
\hline Material deprivation Q1 & & 1.00 & & 1.00 \\
\hline Q5 & & $1.14(0.54$ to 2.40$)$ & & 0.69 (0.24 to 1.98$)$ \\
\hline Social isolation Q1 & & 1.00 & & 1.00 \\
\hline Q5 & & 1.86 (1.01 to 3.42$)$ & & $2.52(0.96$ to 6.61$)$ \\
\hline
\end{tabular}

Source: Census of Canada 2006; Canadian Community Health Survey 2007-2011.

Individual risk factors in the adjusted models are: age, marital status, home ownership, having dependent children, employment status, overweight or obese, physical activity level, smoking status, educational level and household income.

challenges in maintaining health above and beyond the socioeconomic condition and social isolation of the communities, and individual demographic, behavioural and socioeconomic attributes. It is still unclear why it is not the most remote communities-where there is most likely less access to health services, opportunities for various social relations and modern amenities-but towns that exert a stronger negative influence on health.

The findings also suggest that health inequality studies based on urban-only settings may underestimate the risks by some factors. For example, the influence of unemployment appears to be much more severe in towns and rural communities than in urban communities in our study. On the other hand, having a relatively low-household income does not seem to be as harmful in non-urban communities. The psychosocial effects ${ }^{29}$ from the status of being unemployed may be more pronounced in non-urban settings, while a (neo)materialist aspect of the effects ${ }^{30}$-not being able to afford goods and services-may be more applicable to urban settings, though they are not entirely 
Table 3 ORs of having at least one of four diseases stratified by settlement type—urban, town and rural, Nova Scotia, 2007-2011

\begin{tabular}{|c|c|c|c|}
\hline & $\begin{array}{l}\text { Urban }(95 \% \mathrm{Cl}) \\
\mathrm{n}=2776\left(\text { yes }^{*}=494\right)\end{array}$ & $\begin{array}{l}\text { Town }(95 \% \mathrm{Cl}) \\
\mathrm{n}=5349 \text { (yes=1355) }\end{array}$ & $\begin{array}{l}\text { Rural }(95 \% \mathrm{Cl}) \\
\mathrm{n}=3108(\text { yes=740) }\end{array}$ \\
\hline \multicolumn{4}{|l|}{ Age } \\
\hline $12-24$ & 1.00 & 1.00 & 1.00 \\
\hline $25-44$ & 3.07 (1.04 to 9.03$)$ & 3.18 (1.68 to 6.00$)$ & 3.51 (1.20 to 10.28$)$ \\
\hline $45-64$ & 16.19 (5.70 to 45.98$)$ & 9.47 (5.08 to 17.66$)$ & 14.07 (4.94 to 40.13$)$ \\
\hline $65+$ & 30.50 (10.39 to 89.53$) \dagger$ & 16.03 (8.48 to 30.33$)$ & 19.97 (6.90 to 57.79$)$ \\
\hline \multicolumn{4}{|l|}{ Gender } \\
\hline Female & 1.00 & 1.00 & 1.00 \\
\hline Male & 0.90 (0.57 to 1.42$)$ & 0.99 (0.74 to 1.34$)$ & 1.15 (0.77 to 1.73$)$ \\
\hline \multicolumn{4}{|l|}{ Marital status } \\
\hline Single & 1.00 & 1.00 & 1.00 \\
\hline Couple & $0.94(0.70$ to 1.28$)$ & $0.99(0.81$ to 1.21$)$ & 0.94 (0.73 to 1.22$)$ \\
\hline \multicolumn{4}{|l|}{ Home ownership } \\
\hline Own home & 1.00 & 1.00 & 1.00 \\
\hline Do not own home & $1.00(0.71$ to 1.39$)$ & 1.18 (0.95 to 1.48$)$ & $1.17(0.78$ to 1.75$)$ \\
\hline \multicolumn{4}{|c|}{ Dependent children (17 years old or less) } \\
\hline No & 1.00 & 1.00 & 1.00 \\
\hline Yes & $0.93(0.57$ to 1.51$)$ & $0.58(0.41$ to 0.81$)$ & 0.63 (0.40 to 1.01$)$ \\
\hline Have kids $\times$ Male & 0.45 (0.18 to 1.08$)$ & $0.49(0.27$ to 0.90$)$ & 0.65 (0.29 to 1.47$)$ \\
\hline \multicolumn{4}{|l|}{ Employed } \\
\hline Yes & 1.00 & 1.00 & 1.00 \\
\hline No & 1.53 (1.09 to 2.14$)$ & 2.31 (1.88 to 2.82$)$ & 2.27 (1.75 to 2.95$)$ \\
\hline Unemployed $\times$ Male & $2.48(1.43$ to 4.30$)$ & $1.16(0.82$ to 1.63$)$ & $1.28(0.82$ to 2.00$)$ \\
\hline \multicolumn{4}{|l|}{ Overweight or obese } \\
\hline No & 1.00 & 1.00 & 1.00 \\
\hline Yes & $1.88(1.41$ to 2.50$)$ & 1.51 (1.26 to 1.81$)$ & 1.81 (1.42 to 2.32$)$ \\
\hline \multicolumn{4}{|l|}{ Activity } \\
\hline Active & 1.00 & 1.00 & 1.00 \\
\hline Moderately active & 1.69 (1.15 to 2.50$)$ & 1.15 (0.90 to 1.47$)$ & $0.86(0.62$ to 1.20$)$ \\
\hline Inactive & 1.90 (1.34 to 2.70$)$ & 1.25 (1.00 to 1.56$)$ & 1.24 (0.94 to 1.64$)$ \\
\hline \multicolumn{4}{|l|}{ Current smoker } \\
\hline No & 1.00 & 1.00 & 1.00 \\
\hline Yes & $1.06(0.77$ to 1.44$)$ & $0.92(0.75$ to 1.13$)$ & 1.01 (0.77 to 1.33$)$ \\
\hline \multicolumn{4}{|l|}{ Educational attainment } \\
\hline Postsecondary & 1.00 & 1.00 & 1.00 \\
\hline Some postsecondary & $1.43(0.83$ to 2.45$)$ & 0.90 (0.62 to 1.29$)$ & 0.88 (0.52 to 1.47$)$ \\
\hline High school diploma & 0.86 (0.58 to 1.28$)$ & 0.91 (0.71 to 1.17$)$ & 0.85 (0.61 to 1.20$)$ \\
\hline No high school & $1.10(0.75$ to 1.60$)$ & $1.11(0.90$ to 1.38$)$ & 0.83 (0.64 to 1.08$)$ \\
\hline \multicolumn{4}{|l|}{ Household income } \\
\hline$>\$ 80000$ & 1.00 & 1.00 & 1.00 \\
\hline$\$ 60000-\$ 79999$ & 1.09 (0.74 to 1.63$)$ & $1.24(0.94$ to 1.64$)$ & $1.08(0.75$ to 1.55$)$ \\
\hline$\$ 40000-\$ 59999$ & $1.11(0.84$ to 1.21$)$ & $1.02(0.79$ to 1.33$)$ & 0.89 (0.62 to 1.27$)$ \\
\hline$\$ 20000-\$ 39000$ & $1.76(1.17$ to 2.65$)$ & $1.25(0.97$ to 1.60$)$ & $1.08(0.78$ to 1.49$)$ \\
\hline$<\$ 20000$ & $1.76(1.00$ to 3.08$)$ & $1.11(0.80$ to 1.52$)$ & $1.44(0.97$ to 2.14$)$ \\
\hline \multicolumn{4}{|l|}{ Contextual variables } \\
\hline \multicolumn{4}{|l|}{ Material deprivation } \\
\hline Q1 & 1.00 & 1.00 & 1.00 \\
\hline Q5 & $0.69(0.17$ to 2.80$) \ddagger$ & 0.60 (0.35 to 1.01$)$ & 1.38 (0.65 to 2.93$)$ \\
\hline \multicolumn{4}{|l|}{ Social isolation } \\
\hline Q1 & 1.00 & 1.00 & 1.00 \\
\hline Q5 & $1.20(0.83$ to 1.74$)$ & $1.06(0.74$ to 1.51$)$ & $1.07(0.66$ to 1.74$)$ \\
\hline
\end{tabular}

Source: Census of Canada 2006; Canadian Community Health Survey 2007-2011.

*'Yes' means reporting at least one of the four diseases.

†The wide ranges of Cls for age are most likely due to the very small cell size, particularly for the youngest age group reporting a disease.

¥Urban communities did not contain the lowest quintile of material deprivation. Therefore, this is the OR of the second lowest quintile.

separate effects. Moreover, the extent of negative influence of being unemployed seems to be more gendered in urban communities. This may be because urban female employment provides more of supplemental income than primary income in a household, while female and male employment incomes may contribute more equally to the 
household income in non-urban communities. Further investigation is necessary to determine whether the differential share of employment income contribution explains this phenomenon.

The stronger effect of inactivity in urban communities could mean that town and rural respondents may engage more in types of physical activities other than leisure or commuting; thus, the overall activity level is underestimated. However, some studies ${ }^{20} 31$ pointed to higher rates of obesity and overweight in semiurban (or semirural) areas, linking to the sedentary lifestyles, the lack of opportunities of physical activities and the need to drive long distances to work and amenities. ${ }^{10}$ The prevalence of obesity in Nova Scotia is, in fact, lower in non-urban communities than in urban communities (data not shown). Measures of household-related activities can be incorporated $^{27}$ to improve the measurement.

The additional protective effect of males having dependants in non-urban communities requires attention. It should be noted that the estimates of the risks were somewhat unstable due to a small number of male respondents with dependants reporting a disease. Nevertheless, some studies found that childless men have higher risks of cardiovascular diseases, some cancers and premature mortality, linking to fertility and associated hormones as potential factors. ${ }^{32-34}$ Risky health behaviours in fathers not living with children and childless men were also reported. ${ }^{33}$ Conversely, males with dependants may tend to have biological and behavioural patterns that reduce the risk of some diseases.

When the reference of gender was reversed, the analysis of interaction (having female dependants) showed a damaging effect (OR 2.02 (95\% CI 1.11 to 3.67$)$ in towns-data not shown). This is inconsistent with the Canadian study ${ }^{27}$ which found a protective effect of females having dependants on hypertension. It is beyond the scope of this study to examine hypertension. The differences in age cut-offs of respondents and dependants, urban-rural inclusive versus urban-only study contexts, and inclusion of different variables in the respective studies (eg, stress level in the said study and employment in our study) may be the contributors to this difference.

Unlike some of the previous studies, ${ }^{35} 36$ communitylevel material deprivation (or social isolation) was not statistically significant for three of the diseases examined after accounting for individual-level characteristics. Nor was there cross-level interaction with gender. It could be due to a narrower difference between communities within the province in socioeconomic characteristics than crossregionally. Nova Scotia is one of the less affluent provinces in Canada, and socioeconomic conditions are relatively homogeneous across communities. Similar studies elsewhere in Canada or internationally, where the differences in socioeconomic conditions are more prominent, may find a more significant influence of material deprivation.

There are several notable limitations to this study. First, the health outcomes employed are self-reported.
A recent study comparing administrative data and CCHS responses $^{37}$ found good agreement for diabetes and hypertension ( $\kappa 0.8$ and 0.66 ), but relatively poor agreement for stroke and acute myocardial infarction $(\kappa 0.36$ and 0.48$)$. It is unclear whether non-reporting tends to occur in certain groups or geographic types. Second, as CCHS is a cross-sectional survey, the cause-effect relationships cannot be clearly determined. It is possible that some of those affected by chronic health problems lost employment, income or other resources, and moved to more deprived communities requiring lower living costs as the result. ${ }^{38}$ Third, some potentially important risk factors were not included. The variable pertaining to alcohol consumption was not included since the question asking the amount of drinking (from which levels of drinking can be determined for each gender) was unanswered by many respondents $(70 \%)$. Ethnicity and language-related disadvantages in health have been shown to exist in Nova Scotia, ${ }^{39} 40$ but the proportions of minority ethnic and language groups are very small, and were not represented sufficiently in many communities. Nor were aboriginal persons on reserves included in the survey. Fourth, some community and individual characteristics may be important for some diseases and not others, as seen in diabetes for which material deprivation and not settlement type (town) was a significant factor. Models for different settlement types could not run for individual diseases due to low frequencies.

The small between-area variance observed indicates that, unlike most other provinces which are much larger in geographic size and include very remote regions, community environments are not substantially dissimilar in Nova Scotia. In spite of this, the findings of this study support the view that urban-rural differences matter in the investigation of small-area health inequalities. ${ }^{11}$ Evidence produced at small-area levels such as the neighbourhood or community is necessary to identify target subpopulations for programmes and policy interventions on a regional scale. Ways to devise meaningful, comparable small-area units for a 'global' comparison ${ }^{20}$ of all communities across the whole of a region should continue to be explored.

Contributors MT conceived the idea for this study, performed the analysis and drafted the manuscript. DCGR and ARL actively contributed to the discussion and interpretation of the ideas and results. All authors critically reviewed the manuscript.

Funding MT was funded by the Canadian Institute of Health Research Postdoctoral Research Fellowship.

Competing interests None.

Provenance and peer review Not commissioned; externally peer reviewed.

Data sharing statement No additional data are available.

Open Access This is an Open Access article distributed in accordance with the Creative Commons Attribution Non Commercial (CC BY-NC 3.0) license, which permits others to distribute, remix, adapt, build upon this work noncommercially, and license their derivative works on different terms, provided the original work is properly cited and the use is non-commercial. See: http:// creativecommons.org/licenses/by-nc/3.0/ 


\section{REFERENCES}

1. Boyle PJ, Gatrell AC, Duke-Williams O. Do area-level population change, deprivation and variations in deprivation affect individual-level self-reported limiting long-term illness? Soc Sci Med 2001;53:795-9.

2. Chaix B, Rosvall M, Merlo J. Neighbourhood socioeconomic deprivation and residential instability: effects on incidence of ischemic heart disease and survival after myocardial infarction. Epidemiology 2007;18:104-11.

3. Pampalon R, Hamel D, Gamache P. A comparison of individual and area-based socio-economic data for monitoring social inequalities in health. Health Rep 2009;20:85-94.

4. Daniel M, Lekkas $P$, Cargo M. Environments and cardiometabolic diseases in aboriginal populations. Heart Lung Circ 2010;19:306-15.

5. Diez Roux AV, Merkin SS, Arnet D, et al. Neighbourhood of residence and incidence of coronary heart disease. $N$ Engl J Med 1997;345:99-106.

6. Chaix B, Leyland AH, Sabel CE, et al. Spatial clustering of mental disorders and associated characteristics of the neighbourhood context in Malmo, Sweden, in 2001. J Epidemiol Community Health 2006;60:427-35.

7. Diez Roux AV, Mair CA. Neighbourhoods and health. Ann N Y Acad Sci 2010;1186:125-45.

8. Matheson FI, Moineddin R, Dunn JR, et al. Urban neighbourhood, chronic stress, gender and depression. Soc Sci Med 2006;63:2604-16.

9. Bell N, Schuurman N, Hayes MV. Using GIS-based methods of multicriteria analysis to construct socio-economic deprivation indices. Int $J$ Health Geogr 2007;6:17.

10. Riva M, Curtis S, Gauvin L, et al. Unravelling the extent of inequalities in health across urban and rural areas: evidence from a national sample in England. Soc Sci Med 2009;68:654-63.

11. Dunbar JA, Peach E. The disparity called rural health: what is it, and what needs to be done? Aust J Rural Health 2012;20:290-2.

12. Haynes R, Gale S. Deprivation and poor health in rural areas: inequalities hidden by averages. Health Place 2000;6:275-85.

13. Veugelers PJ, Yip AM, Burge F. Inequalities in health and health service delivery: a multilevel study of primary care and hypertension control. Chronic Dis Can 2004;25:101-7.

14. Public Health Agency of Canada. Disease Surveillance On-Line. 2012

15. Nova Scotia Community Counts. Government of Nova Scotia. 2010.

16. Sampson RJ. The neighbourhood context of well-being. Perspect Biol Med 2003;46 (Suppl):S53-64

17. Sampson RJ, Morenoff JD, Cannon-Rowley T. Assessing "neighbourhood effects": social processes and new directions in research. Ann Rev Sociol 2002;28:443-78.

18. Ross NA, Tremblay S, Graham K. Neighbourhood influences on health in Montreal, Canada. Soc Sci Med 2004;59:1485-94.

19. Stafford M, Duke-Williams O, Shelton N. Small area inequalities in health: are we underestimating them? Soc Sci Med 2008;67:891-9.

20. Pampalon R, Martinez J, Hamel D. Does living in rural areas make a difference for health in Québec? Health Place 2006;12: 421-35.

21. Terashima M. Geographical epidemiology of health and deprivation: a population-based, spatio-temporal analysis of health and social inequality in Nova Scotia, Canada. Ph.D. dissertation. Dalhousie University, 2011.

22. Terashima M, Read Guernsey J, Andreou P. What type of rural? Assessing the variations in life expectancy at birth at small area-level for a small population province using classes of locally defined settlement types. BMC Public Health 2014;14:162.

23. Statistics Canada. Canadian Community Health Survey annual component-public use microdata file, 2009-2010 derived variable (DV) specifications. Ottawa, 2011.

24. Guo G, Zhao H. Multilevel modeling for binary data. Ann Rev Socio 2000;26:441-62.

25. Artazcoz L, Benach J, Borrell C, et al. Unemployment and mental health: understanding the interactions among gender, family roles, and social class. Am J Public Health 2004;94:82.

26. Sundquist K, Malmstrom M, Johansson SE. Neighbourhood deprivation and incidence of coronary heart disease: a multilevel study of 2.6 million women and men in Sweden. J Epidemiol Community Health 2004;58:71-7.

27. Matheson FI, White HL, Moineddin R, et al. Neighbourhood chronic stress and gender inequalities in hypertension among Canadian adjuts: a multilevel analysis. J Epidemiol Community Health 2010;64:705-13.

28. Stjarne MK, Diderichsen F, Reuterwall C, et al. Socioeconomic context in area of living and risk of myocardial infarction: results from Stockholm Heart Epidemiology Program (SHEEP). J Epidemiol Community Health 2002;56:29-35.

29. Wilkinson R. The impact of inequality: how to make sick societies healthier. New York: New Press, 2005

30. Dunn JR, Veenstra G, Ross N. Psychosocial and neo-material dimensions of SES and health revisited: predictors of self-rated health in a Canadian national survey. Soc Sci Med 2005;62:1465-73.

31. Eberhardt MS, Pamuk ER. The importance of place of residence: examining health in rural and nonrural areas. Am J Public Health 2004:94:1682-6.

32. Eisenberg ML, Park Y, Hollenbeck AR, et al. Fatherhood and the risk of cardiovascular mortality in the NIH-AARP Diet and Health Study. Hum Reprod 2011;26:3479-85.

33. Ringback Weitoft G, Burstrom B, Rosen M. Premature mortality among lone fathers and childless men. Soc Sci Med 2004;59:1449-59.

34. Khaw K, Dowsett M, Folkerd E, et al. Endogenous testosterone and mortality due to all causes, cardiovascular disease, and cancer in men: European prospective investigation into cancer in Norfolk (EPIC-Norfolk) Prospective Population Study. Circulation 2007;116:2694-701.

35. Dupont MA, Pampalon R, Hamel D. Deprivation and cancer mortality among Quebec women and men, 1994-1998. Institut National De Santé Publique Du Québec, 2004:1-12.

36. Lang IA, Llewellyn DJ, Langa KM, et al. Neighbourhood deprivation and incident mobility disability in older adults. Age Ageing 2008;37:403-10.

37. Muggah E, Graves E, Bennett C, et al. Acertainment of chronic diseases using population health data: a comparison of health administrative data and patient self-report. BMC Public Health 2013;13:16.

38. Boyle PJ, Duke-Williams O, Eds. Does migration exaggerate the relationship between deprivation and self-reported limiting long-term illness? Soc Sci Med 2002;55:21-31.

39. Kisely S, Terashima M, Langille D. A population-based analysis of the health experience of African Nova Scotians. Can Med Assoc J 2008;179:653-8.

40. Langille D, Rainham D, Kisely $S$. Is Francophone language status associated with differences in the health services use of rural Nova Scotians? Can J Public Health 2012;103:65-8. 